\title{
A novel missense mutation in the signal peptide of the human POMC gene: a possible additional link between early-onset type 2 diabetes and obesity
}

\begin{abstract}
Monica Mencarelli ${ }^{1,3}$, Alessandra Zulian ${ }^{2,3}$, Raffaella Cancello ${ }^{1}$, Luisella Alberti ${ }^{2}$, Luisa Gilardini ${ }^{2}$, Anna Maria Di Blasio ${ }^{\star, 1}$ and Cecilia Invitti ${ }^{2}$

Rare mutations in several genes have a critical role in the control of homeostatic mechanisms such as food-intake, energy balance and glucose metabolism. In this study, we performed a mutational screening in a 58-year-old woman presenting early-onset type 2 diabetes and central obesity. The entire coding regions of MC4R, MC3R, HNF1A, GCK and POMC (pro-opiomelanocortin) genes were analyzed by direct sequencing. A new missense mutation was identified within the POMC gene signal peptide sequence, resulting in a heterozygous substitution of an arginine for a glycine at codon 15 (p.A15G) that was excluded in $\mathbf{3 0 0}$ healthy normal weight controls. The mutation segregated in the family and was associated with overweight, type 2 diabetes, hypertension and coronary heart disease in the carriers. Functional studies demonstrated that POMC protein was not detectable in $\beta$-TC3 cells transfected with A15G-POMC vector as well as in their culture media, despite POMC mRNA levels were comparable for amount and stability to those of wild-type-transfected cells. In silico RNA folding prediction indicated that the mutation gives rise to a different RNA secondary structure, suggesting that it might affect translation and protein synthesis. To the best of our knowledge, this is the first report addressing the functional consequences of a mutation in the signal peptide of POMC. These findings further support the hypothesis that POMC-derived peptides might have a role in the control of peripheral glucose metabolism and suggest that disruption of central POMC secretion might represent an additional link between type 2 diabetes and obesity.
\end{abstract}

European Journal of Human Genetics (2012) 20, 1290-1294; doi:10.1038/ejhg.2012.103; published online 30 May 2012

Keywords: pro-opiomelanocortin; POMC gene; signal peptide; RNA folding; obesity; diabetes

\section{INTRODUCTION}

Pro-opiomelanocortin (POMC) is a precursor polypeptide hormone produced in neurons of the arcuate nucleus of the hypothalamus, in neurons of the commissural nucleus of the solitary tract of the brainstem, in the pituitary gland, in skin and in several others peripheral tissues, including reproductive organs. ${ }^{1}$ A wide range of biologically active peptides controlling skin and hair pigmentation, as well as adrenal functions, derive from this precursor after a tissuespecific, post-translational cleavage processing. ${ }^{1}$ Moreover, it is well established that POMC-expressing neurons have a critical role in the control of homeostatic mechanisms such as food-intake, energy balance and glucose metabolism. ${ }^{2,3}$ POMC-null mice survive with minimal adrenal gland tissue and undetectable glucocorticoid levels. ${ }^{4}$ Both heterozygous and homozygous mice develop obesity that is gene-dose dependent, and are severely hyperphagic and insulin resistant. ${ }^{4-6}$ The first human $P O M C$-null mutation was detected in two children congenitally lacking $P O M C$ gene products. ${ }^{7}$ Differently from mice, humans carrying $P O M C$-null mutations do not survive without glucocorticoid supplementation from birth. ${ }^{7}$ In addition, they often present with red hair, hyperphagia and obesity. ${ }^{8-15}$ The remarkable similarity between murin and human phenotypes suggests a conserved role for POMC gene in the regulation of energy homeostasis. Interestingly, the study of a large pedigree of one of these patients suggested that even heterozygosis for POMC-null mutation increases the obesity risk. ${ }^{9}$

We here describe a new missense mutation within the signal peptide of $P O M C$ in a woman affected by early onset type 2 diabetes, central obesity and hyperphagia, and report the results of in vitro studies assessing its functional consequences.

\section{MATERIALS AND METHODS}

\section{Patient description}

A 58-year-old caucasian woman developed type 2 diabetes when she was 13 , and came to our observation for poor glycemic control. Her mother had type 2 diabetes, arterial hypertension and coronary artery disease and gave birth to 10 macrosomic newborns. The patient was born at 7 months weighing $4.5 \mathrm{~kg}$. At the age of 30 she also had a macrosomic female newborn. Over the years, the patient developed obesity, arterial hypertension, coronary artery disease, nonproliferative retinopathy and sensory motor neuropathy. On physical examination, she had central obesity (BMI $32 \mathrm{~kg} / \mathrm{m}^{2}$, waist circumference $113 \mathrm{~cm}$ ) with an evident buffalo hump. The skeletal muscle mass at upper and lower limbs was reduced, as assessed by dual energy X-ray absorptiometry. Blood pressure and heart rate were $150 / 85 \mathrm{~mm} \mathrm{Hg}$ and 70 beats/min on lisinopril and metoprolol therapy. Testing for autoantibodies (ICA, anti-GAD, anti-insulin) was negative and insulin levels were elevated $(37 \mu \mathrm{U} / \mathrm{ml})$ while on $2500 \mathrm{mg} / \mathrm{die}$ of metformin and 52 units/die of insulin analogs. The hypothalamic-pituitaryadrenal function was normal. The resting energy expenditure, evaluated by

${ }^{1}$ Laboratory of Molecular Biology, Istituto Auxologico Italiano, Milano, Italy; ${ }^{2}$ Department of Medical Sciences and Rehabilitation, Istituto Auxologico Italiano, Milano, Italy 3These authors contributed equally to this work.

*Correspondence: Dr AM Di Blasio, Laboratory of Molecular Biology, Istituto Auxologico Italiano, Via Zucchi 18, 20095 Cusano Milanino, Milano, Italy. Tel: +39 02619112576; Fax: +39 02619113033; E-mail: a.diblasio@auxologico.it

Received 15 November 2011; revised 27 March 2012; accepted 24 April 2012; published online 30 May 2012 
indirect calorimetry was $1734 \mathrm{kcal} /$ die. When sodium intake was drastically limited, an improvement in glucose tolerance was observed. The patient underwent genetic assessment by mutational screening for MC4R, MC3R, HNF1A, GCK and POMC genes.

The study was approved by the ethics committee of Istituto Auxologico Italiano. Written informed consents were provided by the patient, all the family members and normal-weight healthy subjects enrolled for study.

\section{Preparation of genomic DNA and DNA sequencing}

Genomic DNA was extracted from white blood cells using a commercial kit (Puregene Blood Core Kit B, Qiagen, Minneapolis, MN, USA). The entire coding regions of $M C 4 R, M C 3 R, H N F 1 A, G C K$ and POMC genes were screened by direct sequencing using the Big Dye Terminator Kit (Applied Biosystem, Foster City, CA, USA) and analyzed on the ABI Prism 3100 automated sequencer (Applied Biosystem). The nucleotide sequence of POMC gene was also analyzed in 300 normal-weight healthy caucasian subjects.

\section{In silico analysis of mutant POMC protein}

In silico analysis of structural and functional consequences of A15G mutation was performed using the PredictProtein on-line software (http://www. predictprotein.org). ${ }^{16}$

\section{Cloning of wild-type (WT) and mutated POMC}

pCMV-XL4 vector containing the WT cDNA sequence for human POMC (NM_000939.2, transcript variant 2) was purchased from OriGene (Rockville, MD, USA). The mutated construct (A15G-POMC) was obtained by site-directed mutagenesis of WT-POMC gene, using the QuickChange Site-Directed Mutagenesis Kit (Stratagene, La Jolla, CA, USA). The WT sequence and the mutated $P O M C$ gene (A15G-POMC) were confirmed by sequence analysis (ABI Prism 3100 automated sequencer, Applied Biosystem). WT and A15G-POMC CDNA, corresponding to the sequence for the signal peptide and the entire $P O M C$ gene, were then cloned in pcDNA3.1 vector (Invitrogen, Carlsbad, CA, USA) with the insertion of M2-Flag (Sigma, St Louis, MO, USA) after the $\beta$-endorphin coding sequence, at the end of the last PC2 cleavage site consensus sequence.

\section{Cell transfections}

$\beta$-TC3 cells were cultured until confluence and then transfected with $1 \mu \mathrm{g}$ of pcDNA3.1 containing WT-POMC or A15G-POMC using Lipofectamine 2000 reagent (Invitrogen). Whole cellular lysates and culture media were collected after $3 \mathrm{~h}$ stimulation with and without forskolin ( $10 \mu \mathrm{M}$, Sigma-Aldrich, Milan, Italy) and 3-isobutyl-1-methylxanthine (IBMX 0.1 mM, Sigma-Aldrich).

\section{Confocal immunofluorescence analysis}

$\beta$-TC3 cells $24 \mathrm{~h}$ after transfection were fixed for $10 \mathrm{~min}$ at room temperature (RT) in $4 \%$ paraformaldehyde, washed in PBS and then stored at $4{ }^{\circ} \mathrm{C}$ until immunostaining. Cells were incubated for $24 \mathrm{~h}$ at $4{ }^{\circ} \mathrm{C}$ with a mouse anti-M2Flag antibody (1:1000, Sigma) diluted in BSA/PBS. Thereafter they were washed three times in BSA/PBS and then incubated for $1 \mathrm{~h}$ at RT with a secondary antibody, a fluorescent anti-mouse Alexa 488 (1:200, Invitrogen) in order to detect POMC protein cellular localization. Nuclei were counterstained with propidium iodide (Invitrogen). Cells were examined using BioRad Radials 2100 confocal system (BioRad, Milan, Italy). Digital capture of images was performed with LaserSharp 2000 software (BioRad).

\section{Protein extraction and western blotting analysis}

Cell extracts or supernatant samples were prepared in SDS sample buffer and boiled for $3 \mathrm{~min}$ at $95^{\circ} \mathrm{C}$. Equal amounts of cell protein or equal volumes of culture supernatant were loaded onto 15\% SDS-polyacrylamide gels and electrophoresis was carried out under reducing conditions, according to the procedure of Laemmli. After electrophoresis, the separated proteins were transferred to a nitrocellulose membrane (Amersham Biosciences, Little Chalfont, Buckinghamshire, UK). Membranes were blocked with Tris-buffered saline (TBS) containing 5\% non-fat powered milk for $2 \mathrm{~h}$ at RT and then incubated overnight at $4{ }^{\circ} \mathrm{C}$ in the same buffer supplemented with a mouse monoclonal antibody raised against Anti-M2-Flag (1:1000, Sigma). The membranes were washed with TBS $0.1 \%$ Tween- 20 and incubated for $1 \mathrm{~h}$ at RT with a secondary antibody (1:4000, horseradish peroxidase-conjugated antimouse antibody, Amersham Biosciences). Enhanced chemiluminescence plus western blot detection system (Amersham Biosciences) was used for protein detection according to the manufacturer's instructions. The membranes containing intracellular proteins were stripped and processed for $\beta$-actin protein detection $(1: 15000$, Sigma-Aldrich, St Louis, MO, USA) in order to assess the correct protein loading.

\section{mRNA stability assay}

For mRNA stability assay, confluent $\beta$-TC3 cells were transfected with either $W T$ - or A15G-POMC plasmids in a single $10-\mathrm{cm}$ dish. After $6 \mathrm{~h}$, transfected cells were split in eight different $35 \mathrm{~mm}$ dishes. Twenty-four hours after transfection, actynomicinD (ActD; $10 \mu \mathrm{g} / \mathrm{ml}$ ) was added to the culture media to block mRNA transcription, and cells were harvested at selected time points (basal, 4, 8 and 24h). Cells were collected in $2 \times$ Laemli sample buffer and RLT buffer (Qiagen) for protein and total RNA extraction, respectively.

\section{Real-time quantitative PCR (RT-qPCR)}

RNA concentrations were quantified spectrophotometrically, and total RNA integrity was verified by agarose gel electrophoresis. The copy DNAs were obtained by reverse-transcription with SuperScript III (Invitrogen) from $500 \mathrm{ng}$ of total RNA. RT-qPCR was used to quantify POMC mRNA levels. For each sample, $10 \mathrm{ng}$ of cDNA template was amplified in duplicate in PCR reactions on an ABI PRISM 7900 (Applied Biosystems). A TaqMan probe labeled with carboxyfluorescein for POMC (Hs01596743_m1) was purchased from Applied Biosystems. Human ribosomal protein LP0 (RPLPO) was used as housekeeping gene (Applied Biosystems). Analyses were performed with SDS 3 software (Applied Biosystems). Cycle threshold $\left(C_{\mathrm{t}}\right)$ was defined as the cycle number at which a significant increase in the fluorescence signal was initially detected. Quantification of unknown samples was performed by calculating $C_{\mathrm{t}}$ values for each sample. POMC mRNA levels were normalized to RPLPO expression for each sample by subtracting the $C_{\mathrm{t}}$ for the housekeeping gene from the $C_{\mathrm{t}}$ for gene of interest, producing a $\Delta C_{\mathrm{t}}$ value. The relative quantification, expressed as arbitrary units, was then obtained by the $2-\Delta \Delta C_{\mathrm{t}}$ method to determine fold-change in different experimental conditions.

\section{RNA secondary structure prediction}

Nucleic acid (RNA) folding, hybridization prediction and extrapolation of free energies using thermodynamic methods were done by Mfold web server, using the default parameters (http://front-end.bioinfo.rpi.edu/applications/ $\operatorname{mfold} /) \cdot{ }^{17,18}$

\section{RESULTS}

\section{Mutational screening}

Although obesity and type 2 diabetes are considered polygenic diseases, recent literature reports summarize the importance of monogenic forms that are generally associated with specific subphenotype characteristics, in particular early onset. On the basis of clinical characteristics of the patient, we undertook a mutational screening of the genes most frequently involved in monogenic forms of obesity and type 2 diabetes. ${ }^{19}$ The sequences of the coding regions of Mc4r, Mc3r, Hnfla and Gck genes did not show any mutations. In contrast, a new missense mutation within the signal peptide of the $P O M C$ sequence, resulting in a heterozygous substitution of an arginine for a glycine at codon 15 (A15G-POMC), was identified. The presence of this mutation was excluded in 300 healthy normal weight controls, indicating that this is not a polymorphism.

\section{Family analysis}

The presence of A15G-POMC mutation was evaluated in six available family members. As indicated in Figure 1, five of the six analyzed subjects were carriers of A15G-POMC in heterozygous form. 


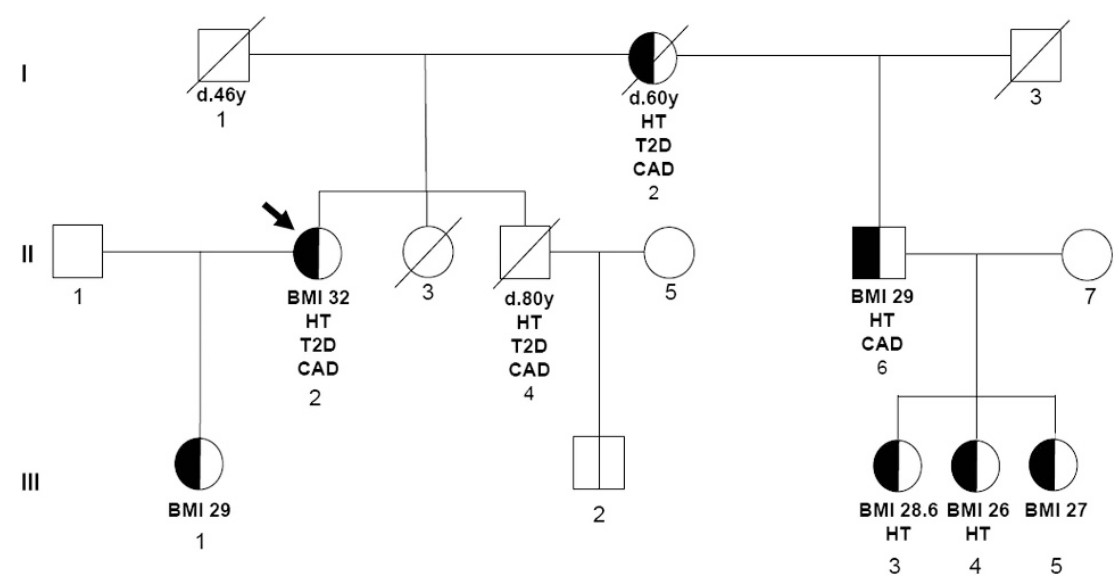

Figure 1 Pedigree of the family. Arrow indicates the proband. Where available, BMI $\left(\mathrm{kg} / \mathrm{m}^{2}\right)$, type 2 diabetes (T2D), coronary artery disease (CAD) and arterial hypertension (HT) are indicated for each subject. The half-filled symbols indicate heterozygosity for the A15G-POMC mutation.

They were all overweight (BMI range $\left.26-29 \mathrm{~kg} / \mathrm{m}^{2}\right)$. The heterozygous brother of the proband had type 2 diabetes coronary artery disease and hypertension. In the third generation, two out of the four carriers were treated for hypertension. As the proband and the carrier brother have different fathers, the mutation was most likely transmitted by the mother (Figure 1).

\section{In silico analysis of $A 15 G$ gene mutation in POMC protein}

To determine whether the mutation identified could have functional implications, before performing in vitro functional studies, we evaluated the possible protein structural consequences of the A15G amino-acid change using the PredictProtein on-line software. ${ }^{16}$ This analysis highlighted an alteration of the alpha helix structure, present at signal peptide level and induced by the mutation (data not shown).

\section{In vitro functional analysis}

To evaluate the functional role of the mutation in the processing and/ or sorting of POMC protein, $\beta$-TC3 cells were transfected with WT and the A15G-POMC plasmids. Intracellular levels of POMC were detected only in WT-transfected cells, whereas $\beta$-TC3 cells transfected with A15G-POMC did not contain the protein product (Figure 2, lysates panel). Similar results were observed after stimulation with forskolin/IBMX. In line with these findings, the whole POMC protein was observed only in culture media of WT unstimulated and stimulated cells (Figure 2, media panel). These findings were also confirmed by confocal analysis (Figure 3 ).

To determine whether the mutation would have any effect on mRNA stability, WT and A15G-POMC-transfected $\beta$-TC3 cells were treated with ActD. As shown in Figure 4a, inhibition of POMC gene transcription was similar in WT- and A15G-POMC-transfected cells, indicating no differences in mRNA stability. POMC protein content decreased accordingly following ActD treatment in WT-transfected cells, while it was undetectable in A15G-POMC-transfected cells at all time points (Figure $4 \mathrm{~b}$ ).

We then used Mfold software to determine in silico if the mutation would have any effect on the formation of different mRNA secondary structures responsible for inhibition of protein translation. A different secondary structure for A15G-POMC mRNA was predicted (Supplementary Figure 1).

In summary, the patient was heterozygous for a new mutation in POMC gene. This mutation was also present, in the same heterozygous form, in several family members. In vitro functional studies

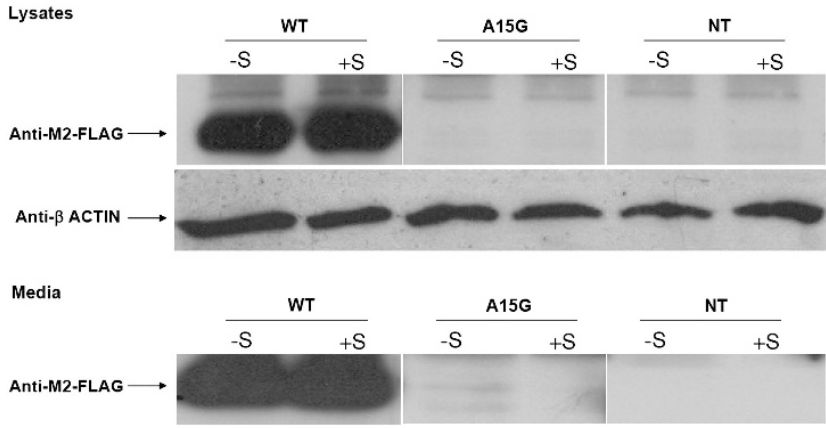

Figure 2 POMC protein detection by western blotting in whole cell lysates and in culture media. Lysates panel: Blot of whole-cell lysates from WTPOMC (WT), A15G-POMC (A15G) and non-transfected (NT) $\beta$-TC3 cells with and without forskolin/IBMX stimulation $(+\mathrm{S} /-\mathrm{S})$. Media panel: Blot of culture media collected from WT, A15G-transfected and NT $\beta$-TC3 cells with and without forskolin/IBMX stimulation $(+S /-S)$.
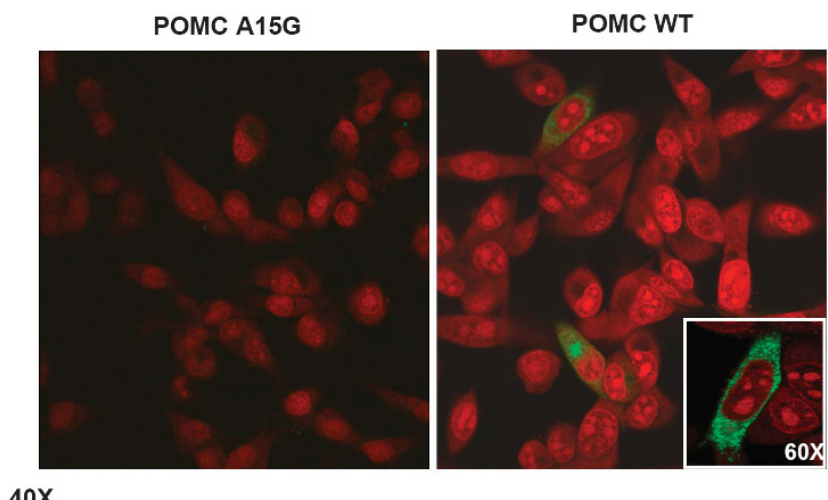

Figure 3 Subcellular localization of POMC protein (green fluorescence) by confocal analysis. WTPOMC and A15G-POMC-transfected $\beta$-TC3 cells are shown. Nuclei were counterstained by propidium iodide. $\times 40$ and $\times 60$ (inset) magnifications are shown.

indicated that the mutation severely compromise POMC synthesis and release.

\section{DISCUSSION}

To date, six cases of human POMC deficiency due to either homozygosity or compound heterozigosity for POMC mutations 

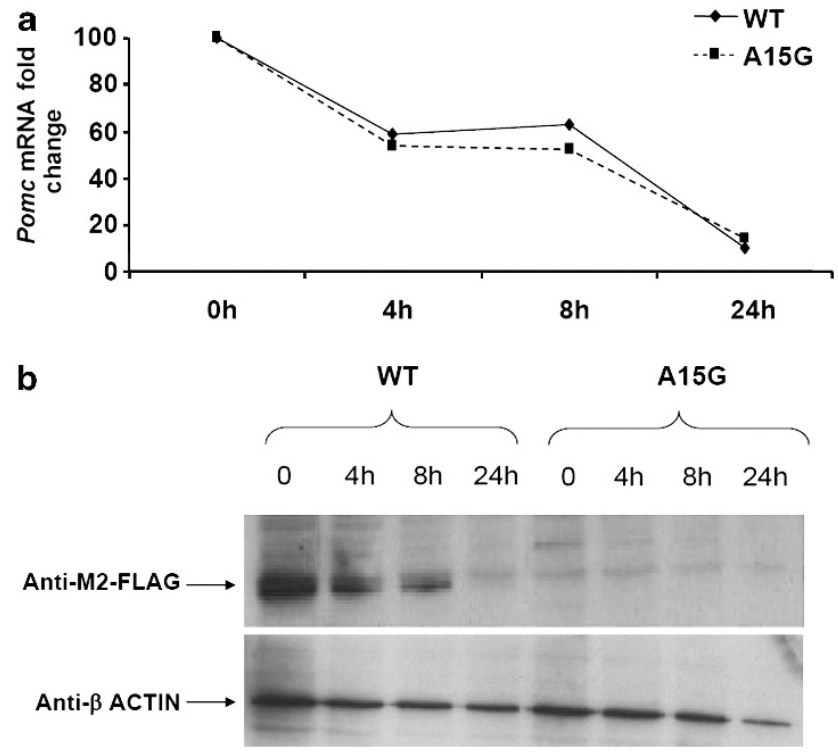

Figure 4 (a) Fold changes of mRNA levels in WTPOMC (WT) and A15GPOMC (A15G)-transfected $\beta$-TC3 cells treated with ActD $(10 \mu \mathrm{g} / \mathrm{ml})$ for 4,8 and $24 \mathrm{~h}$. (b) POMC proteins in WT and A15G-transfected $\beta$-TC3 cells treated with ActD $(10 \mu \mathrm{g} / \mathrm{ml})$ for 4,8 and $24 \mathrm{~h}$. $\beta$-Actin immunoblotting is shown as a control of protein loading.

have been described. ${ }^{7-9}$ The phenotypic characteristics of the patients bearing these mutations include hyperphagia, obesity, glucocorticoid deficiency and altered skin and hair pigmentation. ${ }^{7-9}$ Noteworthy, obesity develops, in both human and animal models, despite glucocorticoid deficiency. ${ }^{4-7}$ Furthermore, POMC-null mice are hypersensitive to the effects of restoring normal glucocorticoid levels. ${ }^{4,6,20}$

The hypothalamic control of energy balance could also be impaired by haploinsufficiency, as suggested by the overweight or obese phenotype of heterozygous carriers of POMC mutations. ${ }^{8,9}$ The majority of these mutations affect either the structure or function of $\alpha$ - and $\beta$-melanocyte-secreting hormone (MSH) or the cleavage from their precursor. ${ }^{9,10,21,22}$ Two rare mutations in the N-terminal region of the $P O M C$ gene, likely affecting processing and sorting of POMC protein to the regulated secretory pathway, have also been associated with early-onset obesity. ${ }^{11}$

In the present study, we describe a new mutation in the signal peptide of the $P O M C$ gene that inhibits the production and then the overall secretion of POMC protein. Indeed, levels of POMC mRNA as well as its stability were comparable in $\beta$-TC3 cells transfected with either WT or A15G-POMC plasmids. Similar findings have been reported for a non-synonymous gene polymorphism in the signal peptide of human TGF- $\beta 1$, which severely impairs protein synthesis. ${ }^{23}$ As for the reported TGF- $\beta 1$ mutation, folding prediction analysis indicated a different RNA secondary structure for the A15G-POMC mRNA. This finding further supports the hypothesis that signal peptide mutations critically compromise mRNA accessibility to the translation machinery, resulting in the absence of the protein product.

The proband was heterozygous for the mutation and had a clinical phenotype that included early-onset type 2 diabetes associated with marked hyperinsulinemia that reflects a condition of insulin resistance. Based on the results reported herein, it is tempting to speculate that the genetic alteration compromising the synthesis of the whole POMC product, even if in heterozygosis, might explain the complex and severe phenotype of the patient. The normal function of the hypothalamic-pituitary-adrenal axis of the patient argues against a dominant negative effect that would impair POMC synthesis also from the WT allele. However, haploinsufficiency of some POMCderived peptides could have local effects on the central melanocortin pathway linked to the clinical alteration observed in the patients and her carrier relatives. Although hyperphagia and obesity can be ascribed to reduced availability of the anorexigenic peptide $\alpha$-MSH, a decreased synthesis of $\gamma$-MSH might be responsible for some of the clinical features of the patient. Indeed, rodents with genetic interruption of normal $\gamma$-MSH signaling ${ }^{24,25}$ display features similar to those observed in our patient, for example, a decrease in muscle mass, an increase in fat mass and resting energy expenditure, hyperinsulinemia and abnormal glucose metabolism (in particular at high sodium diet). ${ }^{26}$ Additional evidence support the involvement of central melanocortin system in the regulation of glucose homeostasis. Hyperinsulinemia is one of the common features among Mc4-Rec knockout animals that later develop hyperglycemia following the same pathophysiological process of human type 2 diabetes. ${ }^{27,28}$ Central administration of a melanocortin agonist increases insulin sensitivity and the number of small-sized adipocytes in diet-induced obese rats. ${ }^{29}$ Furthermore, in rats, blockade of neuronal MC3-R and MC4-R by their antagonist SHU9119 induces insulin resistance even when changes in body weight are prevented by controlling food intake. ${ }^{30}$ Taken together, these findings support the hypothesis that intact neuronal melanocortin signaling is required for normal insulin sensitivity in peripheral tissues, independently of its effect on energy balance. The downstream mechanisms by which melanocortins modulate peripheral insulin actions have not been completely elucidated. Likely, these effects are, at least in part, linked to the stimulation of autonomic outflow to the liver, adipose cells and/or skeletal muscle. ${ }^{31-33}$ In addition, melanocortin system has been recently shown to modulate insulin signaling via c-Jun $\mathrm{N}$-terminal kinase activity. ${ }^{34}$

Impairment of POMC protein synthesis was associated, in our patient, with a Cushingoid phenotype and severe metabolic alterations despite the normal hypothalamic-pituitary-adrenal function. This sits easily with the observation that $P O M C$-null mice are hypersensitive to adverse effects of glucocorticoids in terms of development and accumulation of fat mass, hyperglycemia and insulin resistance. ${ }^{4,6}$ The glucocorticoid hypersensitivity and the consequent metabolic syndrome-like phenotype of $P O M C$-null mice have been ascribed to high corticosterone-induced adipose mRNA expression of $11 \beta$-hydoxysteroid-dehydrogenase type 1 (11 $\beta$-HSD1) and high liver expression of glucocorticorticoid receptors. ${ }^{4,20}$ In humans, selective $11 \beta$-HSD1 inhibitors are able to improve insulin sensitivity, glucose control, lipid profiles and atherosclerosis. ${ }^{35}$

In conclusion, we have described a new human POMC gene mutation that, in vitro, completely abolish POMC protein synthesis/ release, and in the studied carriers is associated with a phenotype of early-onset type 2 diabetes and/or overweight/obesity. To the best of our knowledge, this is the first report addressing the functional consequences of a mutation in the signal peptide of POMC. These findings further support previous evidence, indicating that disruption of the hypothalamic POMC secretion might represent an additional link between type 2 diabetes and obesity, providing new insights into the pathogenesis of early onset insulin resistance in humans.

\section{CONFLICT OF INTEREST}

The authors declare no conflict of interest. 


\section{ACKNOWLEDGEMENTS}

We would like to thank the patient and her relatives for the kind collaboration.

1 Mountjoy KG: Functions for pro-opiomelanocortin-derived peptides in obesity and diabetes. Biochem J 2010; 428: 305-324.

2 Parton LE, Ye CP, Coppari R et al: Glucose sensing by POMC neurons regulates glucose homeostasis and is impaired in obesity. Nature 2007; 449: 228-232.

3 Fick LJ, Belsham DD: Nutrient sensing and insulin signaling in neuropeptideexpressing immortalized, hypothalamic neurons: A cellular model of insulin resistance. Cell Cycle 2010; 9: 3186-3193.

4 Coll AP, Challis BG, Lopez M, Piper S, Yeo GS, O'Rahilly S: Proopiomelanocortindeficient mice are hypersensitive to the adverse metabolic effects of glucocorticoids. Diabetes 2005; 54: 2269-2276.

5 Coll AP: Effects of pro-opiomelanocortin (POMC) on food intake and body weight: mechanisms and therapeutic potential? Clin Sci (Lond) 2007; 113: 171-182.

6 Coll AP, Loraine Tung YC: Pro-opiomelanocortin (POMC)-derived peptides and the regulation of energy homeostasis. Mol Cell Endocrinol 2009; 300: 147-151.

7 Krude H, Biebermann H, Luck W, Horn R, Brabant G, Gruters A: Severe early-onset obesity, adrenal insufficiency and red hair pigmentation caused by POMC mutations in humans. Nat Genet 1998; 19: 155-157.

8 Krude $H$, Biebermann $H$, Schnabel D et al: Obesity due to proopiomelanocortin deficiency: three new cases and treatment trials with thyroid hormone and ACTH4-10. J Clin Endocrinol Metab 2003; 88: 4633-4640.

9 Farooqi IS, Drop S, Clements A et al: Heterozygosity for a POMC-null mutation and increased obesity risk in humans. Diabetes 2006; 55: 2549-2553.

10 Lee YS, Challis BG, Thompson DA et al: A POMC variant implicates beta-melanocytestimulating hormone in the control of human energy balance. Cell Metab 2006; 3 : 135-140.

11 Creemers JW, Lee YS, Oliver RL et al: Mutations in the amino-terminal region of proopiomelanocortin (POMC) in patients with early-onset obesity impair POMC sorting to the regulated secretory pathway. J Clin Endocrinol Metab 2008; 93 4494-4499.

12 Miraglia del Giudice E, Cirillo G, Santoro N et al: Molecular screening of the proopiomelanocortin (POMC) gene in Italian obese children: report of three new mutations. Int J Obes Relat Metab Disord 2001; 25: 61-67.

13 Santoro N, del Giudice EM, Cirillo G et al: An insertional polymorphism of the proopiomelanocortin gene is associated with fasting insulin levels in childhood obesity. J Clin Endocrinol Metab 2004; 89: 4846-4849.

14 Santoro N, Perrone L, Cirillo G et al: Weight loss in obese children carrying the proopiomelanocortin R236G variant. J Endocrinol Invest 2006; 29: 226-230.

15 Tortorella A, Monteleone P, del Giudice EM et al: Melanocortin-4 receptor molecular scanning and pro-opiomelanocortin R236G variant screening in binge eating disorder. Psychiatr Genet 2005; 15: 161.

16 Rost B, Liu J: The PredictProtein server. Nucleic Acids Res 2003; 31: 3300-3304.

17 Zuker M: Mfold web server for nucleic acid folding and hybridization prediction. Nucleic Acids Res 2003; 31: 3406-3415.
18 Zuker M, Stiegler P: Optimal computer folding of large RNA sequences using thermodynamics and auxiliary information. Nucleic Acids Res 1981; 9: 133-148.

19 O'Rahilly S: Human genetics illuminates the paths to metabolic disease. Nature 2009, 462: 307-314.

20 Michailidou Z, Coll AP, Kenyon CJ et al: Peripheral mechanisms contributing to the glucocorticoid hypersensitivity in proopiomelanocortin null mice treated with corticosterone. J Endocrinol 2007; 194: 161-170.

21 Challis BG, Pritchard LE, Creemers JW et al: A missense mutation disrupting a dibasic prohormone processing site in pro-opiomelanocortin (POMC) increases susceptibility to early-onset obesity through a novel molecular mechanism. Hum Mol Genet 2002; 11: 1997-2004.

22 Biebermann $\mathrm{H}$, Castaneda TR, van Landeghem $\mathrm{F}$ et al: A role for beta-melanocytestimulating hormone in human body-weight regulation. Cell Metab 2006; 3 141-146.

23 Mohren S, Weiskirchen R: Non-synonymous gene polymorphisms in the secretory signal peptide of human TGF-betal affect cellular synthesis but not secretion of TGF-beta1. Biochem Biophys Res Commun 2009; 379: 1015-1020.

24 Butler $\mathrm{AA}$, Kesterson RA, Khong $\mathrm{K}$ et al: $\mathrm{A}$ unique metabolic syndrome causes obesity in the melanocortin-3 receptor-deficient mouse. Endocrinology 2000; 141 3518-3521.

25 Chen AS, Marsh DJ, Trumbauer ME et al: Inactivation of the mouse melanocortin-3 receptor results in increased fat mass and reduced lean body mass. Nat Genet 2000; 26: 97-102.

$26 \mathrm{Ni}$ XP. Humphreys $\mathrm{MH}$. Abnormal glucose metabolism in hypertensive mice with genetically interrupted gamma-melanocyte stimulating hormone signaling fed a highsodium diet. Am J Hypertens 2008; 21: 1284-1287.

27 Fan W, Dinulescu DM, Butler AA, Zhou J, Marks DL, Cone RD: The centra melanocortin system can directly regulate serum insulin levels. Endocrinology 2000, 141: 3072-3079.

28 Huszar D, Lynch CA, Fairchild-Huntress V et al: Targeted disruption of the melanocortin-4 receptor results in obesity in mice. Cell 1997; 88: 131-141.

29 Banno R, Arima H, Hayashi $M$ et al: Central administration of melanocortin agonist increased insulin sensitivity in diet-induced obese rats. FEBS Lett 2007 581: 1131-1136.

30 Obici S, Feng Z, Tan J, Liu L, Karkanias G, Rossetti L: Central melanocortin receptors regulate insulin action. J Clin Invest 2001; 108: 1079-1085.

31 Barzilai N, She L, Liu L et al: Decreased visceral adiposity accounts for leptin effect on hepatic but not peripheral insulin action. Am J Physiol 1999; 277: E291-E298.

32 Liu L, Karkanias GB, Morales JC et al: Intracerebroventricular leptin regulates hepatic but not peripheral glucose fluxes. J Biol Chem 1998; 273: 31160-31167.

33 Stanley S, Pinto S, Segal J et al: Identification of neuronal subpopulations that project from hypothalamus to both liver and adipose tissue polysynaptically. Proc Natl Acad Sci USA 2010; 107: 7024-7029.

34 Chai B, Li JY, Zhang W, Wang H, Mulholland MW: Melanocortin-4 receptor activation inhibits c-Jun $\mathrm{N}$-terminal kinase activity and promotes insulin signaling. Peptides 2009; 30: 1098-1104.

35 Minder El: Afamelanotide an agonistic analog of alpha-melanocyte-stimulating hormone, in dermal phototoxicity of erythropoietic protoporphyria. Expert Opin Investig Drugs 2010; 19: 1591-1602.

Supplementary Information accompanies the paper on European Journal of Human Genetics website (http://www.nature.com/ejhg) 